
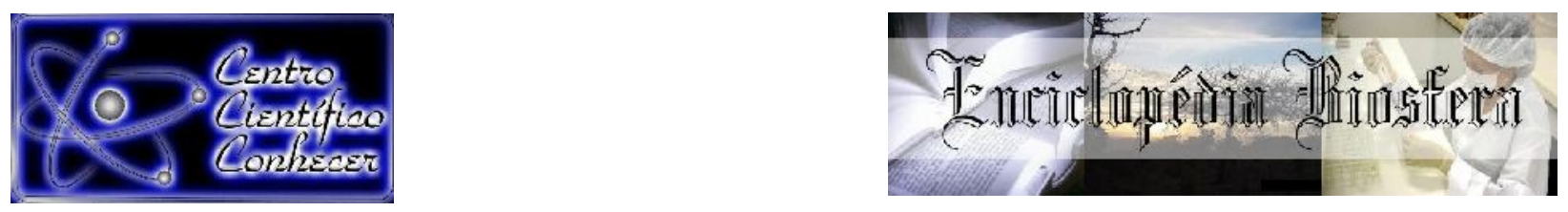

\title{
MÚSICA COMO FERRAMENTA DE EDUCAČ̃̃O AMBIENTAL PARA ALUNOS DO ENSINO MÉDIO
}

\footnotetext{
Renan Luiz Albuquerque Vieira ${ }^{1}$, Hanilton Ribeiro de Souza ${ }^{2}$, Rafael Luiz de Albuquerque Vieira ${ }^{3}$, Maria Vanderly Andrea ${ }^{4}$

${ }^{1}$ Programa de Pós-Graduação em Ciência Animal Nos Trópicos, Universidade Federal da Bahia, Salvador, Brasil - (renan.albuquerque@hotmail.com)

${ }^{2}$ Docente da Universidade do Estado da Bahia, Santo Antônio de Jesus, Brasil

${ }^{3}$ Licenciado em Geografia pela Universidade do Estado da Bahia, Santo Antônio de Jesus, Brasil

${ }^{4}$ Docente da Universidade Federal do Recôncavo da Bahia, Cruz das Almas, Brasil

Recebido em: 15/11/2020 - Aprovado em: 15/12/2020 - Publicado em: 30/12/2020

DOI: 10.18677/EnciBio_2020D26
}

\begin{abstract}
RESUMO
O meio ambiente tem sofrido profundas alterações devido a ações antrópicas, e este, é o grande desafio que se coloca à pedagogia ambiental, formar um senso crítico e reflexivo no ser humano, desde a infância e juventude, partindo de sua realidade, mas também visando em nível global, a fim de que se compreenda a complexidade, diversidade e as inter-relações entre sociedade-natureza. Partindo deste princípio, objetivou-se realizar debates oportunos e necessários sobre o meio ambiente, mas também trazer à tona discussões conflitantes e desconfortáveis, à medida que questionam o modelo atual de desenvolvimento, bem como os modos de ser/viver, perceber e agir sobre a natureza. Neste estudo utilizou-se das Rodas de Conversa, como dispositivo metodológico, e da música Absurdo (Vanessa da Mata), como estratégia pedagógica, nas atividades desenvolvidas durante a Semana do Meio Ambiente, com cinco turmas da 3a Série do Ensino Médio, totalizando 200 alunos, do Colégio Estadual Polivalente de Castro Alves. A realização das rodas de conversa nas aulas, bem como, a utilização da música como estratégia pedagógica, estimularam a produção e a partilha horizontal, transversal, autônoma e reflexiva do conhecimento sobre Educação Ambiental. Evidenciou-se que a música constitui-se em uma estratégia pedagógica que propicia reflexão para a produção do conhecimento, contribuindo para trabalhar a Educação Ambiental de maneira efetiva, pois estimulou e agregou importantes contribuições no âmbito da conservação ambiental e sustentabilidade.
\end{abstract}

PALAVRAS-CHAVE: Ensino; Estratégia pedagógica; Sensibilização.

\section{MUSIC AS AN ENVIRONMENTAL EDUCATION TOOL FOR HIGH SCHOOL STUDENTS}

\section{ABSTRACT}

The environment has undergone profound changes due to anthropic actions, and this is the great challenge for environmental pedagogy, to form a critical and reflective sense in human beings, since childhood and youth, starting from their reality, but also aiming at global level, so that he understands the complexity, diversity and the 
interrelationships between society and nature. Based on this principle, aimed to have timely and necessary debates about the environment, but also to bring up conflicting and uncomfortable discussions, as they question our current development model, as well as our ways of being/living, perceiving and acting on the nature. In this study, conversation wheels were used as a methodological device, and Absurd music (Vanessa da Mata), as a pedagogical strategy, in the activities developed during Environment Week, with five classes from the $3^{\circ}$ Series of Medium School, totaling 200 students, from the Public school Polivalente de Castro Alves. The realization of conversation circles in classes, as well as the use of music as a pedagogical strategy, stimulated the production and horizontal, transversal, autonomous and reflective sharing of knowledge about Environmental Education. It became evident that music is a pedagogical strategy that provides reflection for the production of knowledge, contributing to work on Environmental Education in an effective way, as it stimulated and added important contributions in the scope of environmental conservation and sustainability.

KEYWORDS: Awareness; Pedagogical strategy; Teaching.

\section{INTRODUÇÃO}

O Brasil é um País de destaque no que se refere à diversidade de espécies e recursos naturais, no entanto a perda da biodiversidade vem crescendo de forma exponencial (CANTARELI et al., 2016). Esta redução de espécies está prioritariamente associada ao processo de antropização (VIEIRA et al., 2019), contudo, este processo é ainda mais crítico nas regiões tropicais, em função da maior diversidade de espécies. A excessiva exploração dos recursos naturais ocasiona drásticas modificações físicas e biológicas nos ecossistemas, desde a perda de espécies a mudanças climáticas, o que, para diversos autores, representa a era do antropocentrismo (MIRANDA et al., 2016).

Diversas alternativas têm sido propostas na tentativa de desacelerar os impactos ambientais, dentre estas a educação ambiental surge como ferramenta mitigadora, apontada por vários autores como um dos caminhos para minimizar tais problemas socioambientais (VIEIRA et al., 2020). Os princípios da educação ambiental baseiam-se na compreensão, conscientização e desenvolvimento de novos padrões de conduta para com o meio ambiente, por meio da utilização racional dos recursos naturais (BURSZTYN; ERIÓ, 2015). A educação ambiental crítica possui um olhar integrado das relações entre seres humanos e natureza, contribuindo para o resgate de valores essenciais para a cidadania (ABREU, 2017).

Segundo Amaral (2005), a educação ambiental não está dissociada da educação geral, neste sentido, a escola desempenha o importante papel na formação de alunos comprometidos com o meio ambiente. Deste modo, a inserção da educação ambiental em uma perspectiva critica ocorre à medida em que o professor assume a postura reflexiva, no âmbito da prática político-pedagógica, motivando e sensibilizando os alunos acerca da sua responsabilidade socioambiental (BERNADES; NEHME, 2017). A partir da compreensão que a educação tradicional não prepara os indivíduos para a complexa realidade global, a educação ambiental torna-se necessária, fazendo parte de um processo contínuo e permanente que deve abranger todos os níveis escolares e etapas da educação formal e informal (ABREU, 2017).

Dentre as diferentes maneiras de se trabalhar a educação ambiental nas escolas, a música se destaca por possuir papel fundamental no processo de socialização e conscientização dos indivíduos acerca dos problemas ambientais 
recorrentes. Neste contexto, o uso da música como estratégia de aprendizagem pode despertar no aluno maior interesse pelos conceitos e conhecimentos trabalhados na sala de aula, tendo em vista o caráter dialógico e participativo desta atividade (BERNADES, NEHME, 2017). Segundo Souza e Conceição (2018), a música em si já é um grande veículo de aprendizado, podendo ser utilizada para o ensino da Geografia, Biologia, História e dos componentes curriculares. A música, como estratégia de aprendizagem, vem sendo utilizada na educação escolar, justamente por aliar aspectos lúdicos e cognitivos, auxiliando no desenvolvimento linguístico e psicomotor do educando (BERTONCELLO; SANTOS, 2002). Logo, pode-se considerar a música como importante recurso didático-pedagógico que auxilia a popularização da ciência.

Segundo Souza e Conceição (2018), o uso da música, como estratégia de ensino e aprendizagem, abre várias possibilidades na sala de aula, tendo em vista que as canções, cujas letras trazem diversos conceitos e conteúdos, podem propiciar diferentes sensações nos alunos, levando-os a analisar de forma autônoma e reflexiva sobre os conhecimentos trabalhados nas diferentes disciplinas curriculares. Os autores supracitados enfatizam que o professor deve oportunizar aos alunos o acesso a outras linguagens e contextos de aprendizagem, a fim de que se supere a pedagogia das certezas e dos saberes consolidados na modernidade. É necessário ir além do status quo e propor situações em que eles possam confrontar e questionar conceitos, ideias e valores, percebendo-se como protagonistas da realidade, a fim de que contribuam para a construção de uma sociedade mais justa e sustentável.

Diante do exposto objetivou-se, realizar debates oportunos e necessários sobre o meio ambiente, questionando o nosso modelo atual de desenvolvimento, utilizando música e rodas de conversas, como alternativa pedagógica que, conectando autonomia, horizontalidade, circularidade e ludicidade, pudesse elevar a percepção dos alunos sobre os conceitos e saberes relativos à Educação Ambiental.

\section{MATERIAL E MÉTODOS}

Este trabalho trouxe uma experiência de ensino e aprendizagem em que, através das rodas de conversa, pode-se conceber o espaço e o tempo da sala de aula sob outra lógica: da verticalidade (professor/alunos) para a horizontalidade (alunos e professor), construindo um círculo de debates sobre questões relacionadas ao meio ambiente, tendo a música Absurdo (Vanessa da Mata) como fomentadora das discussões encaminhadas pelos alunos. Ao professor, neste processo horizontal de produção do conhecimento, coube assumir uma postura funcional para coordenar e incitar questionamentos, quando necessário (WELLER, 2013).

Esta estratégia foi planejada e executada nas aulas de Geografia durante a Semana do Meio Ambiente, no Colégio Estadual Polivalente de Castro Alves, com 200 alunos das turmas da $3^{\text {a }}$ série do Ensino Médio, ano de 2018. As discussões encaminhadas pelos alunos demonstraram a transversalidade da Educação Ambiental, à medida que surgiram temas e conceitos relacionados aos conteúdos de diversas disciplinas. Assim, evidenciou-se a necessidade da interdisciplinaridade para a realização de situações de aprendizagem relativas a esta e outras temáticas, explicando que se deve romper as barreiras que fragmentam e confinam o conhecimento científico em disciplinas, a fim de proporcionar uma formação mais holística do sujeito para a construção de uma sociedade mais sustentável. 
Foi apresentado um roteiro básico com o intuito de que os colegas que desejassem experienciar com seus alunos esta estratégia de aprendizagem pudesse adaptá-la aos seus objetivos e realidade, inclusive trabalhando-a com/em outras disciplinas:

Anteriormente à Semana do Meio Ambiente, foi construído com os alunos, a partir das discussões de Weller (2013), algumas orientações básicas sobre o funcionamento das rodas de conversa', que ocorreram em duas aulas. Estas orientações foram copiadas no quadro/caderno e foram exibidas via projetor multimídia a cada roda de conversa.

$\checkmark \quad$ Foram apresentadas algumas canções relativas ao tema Meio Ambiente, sendo escolhida a canção Absurdo (Vanessa da Mata). Assim, os alunos tiveram tempo para ouvir, ler e destacar questionamentos/conteúdos presentes na música, antes da realização das rodas de conversa.

$\checkmark \quad \mathrm{Na}$ abertura da roda de conversa, via projetor multimídia, foi exibida a letra e o videoclipe da música escolhida. Os alunos tiveram acesso a letra da canção através do Smartphone ${ }^{2}$.

$\checkmark \quad$ Os alunos encaminharam as discussões, perpassando por temas e conteúdos relativos à Geografia, Biologia, Sociologia, Filosofia e outras disciplinas do currículo.

$\checkmark \quad$ Ao final do círculo foi feita a avaliação dos alunos sobre a atividade.

As rodas de conversa - do ponto de vista metodológico, e a música, enquanto estratégia de aprendizagem, se mostraram promissoras para o ensino e aprendizagem que substitua a pedagogia das certezas e dos saberes consolidados para a pedagogia da pergunta e da complexidade, trabalhando com conceitos transversais, de forma horizontal, estando aberto para os questionamentos, reflexões e o embate de ideias (ASSMANN, 2003).

É preciso destacar que a música, como estratégia pedagógica, subsidiou e impulsionou as discussões, fazendo com que os alunos sublinhassem para discussão vários conteúdos relativos à crise ambiental que está sendo vivenciada.

Abaixo o Quadro 1 relaciona as temáticas identificadas pelos alunos.

QUADRO 1: Letra da música Absurdo (Vanessa da Mata) utilizada como estratégia pedagógica para sensibilização dos alunos sobre os conceitos e saberes relativos à Educação Ambiental.

Absurdo - Vanessa da Mata (2007) Temáticas identificadas pelos alunos

Havia tanto pra Ihe contar. A natureza.

Mudava a forma o estado e o lugar. Era absurdo.
A diversidade de biomas e ecossistemas da Terra.

As diferenças espaciais e ambientais: clima, vegetação, fauna e a formação geomorfológica.

\footnotetext{
${ }^{1}$ Orientações básicas para as rodas de conversa: I- a confiança e o respeito mútuo entre os participantes; II- a discussão será encaminhada e dirigida pelo grupo, a fim de redefinir a lógica socioespacial da escola: vertical para horizontal; III- os questionamentos e argumentações não deverão ser direcionados a um membro específico, mas ao grupo. Àquele que desejar participar da discussão, se inscreverá; IV- os alunos escolherão um relator e um coordenador para ordenar as intervenções dos colegas; V- Deverá ser respeitado o momento da argumentação de cada membro; VI- o professor poderá intervir apenas para realizar questionamentos ou sanar dúvidas. Após a percepção do esgotamento das discussões, ele poderá requer esclarecimentos sobre determinados temas que não ficaram bem claros (WELLER, 2013).

2 Decidimos não distribuir a letra impressa da canção, tendo em vista as discussões e a necessidade de sustentabilidade, na teoria e na prática. Assim, acordamos que os alunos fizessem o download da letra da música via Smartphone.
} 
Tapetes fartos de folhas e flores. Ideologia urbano-industrial que opõe $O$ chão do mundo se varre aqui. Essa ideia do natural ser sujo.

Do inorgânico não se faz. homem e natureza; civilização e meio ambiente.

Destruição é reflexo do humano. Se a ambição desumana o Ser. Essa imagem infértil do deserto. Nunca pensei que chegasse aqui.

Auto-destrutivos, Falsas vítimas nocivas?
Capitalismo industrial e consumismo. Etica e comportamento humano.

Desertificação.

Educação Ambiental.

Ética e responsabilidade ambiental Capitalismo
Havia tanto pra aproveitar. Sem poderio.

Tantas histórias, tantos sabores. Capins dourados.

Havia tanto pra respirar. Era tão fino.

Naqueles rios a gente banhava.

Desmatam tudo e reclamam do tempo.

Que ironia conflitante ser.

Desequilíbrio que alimenta as pragas.

Alterado grão, alterado pão.

Sujamos rios, dependemos das águas.

Tanto faz os meios violentos.

Luxúria é ética do perverso vivo. Morto por dinheiro.

Cores, tantas cores.

Tais belezas.

Foram-se.

Versos e estrelas.

Tantas fadas que eu não vi.

Falsos bens, progresso?

Com a mãe, ingratidão.

Deram o galinheiro

Pra raposa vigiar.
Destruição ambiental.

Perda da diversidade cultural.

Memória, cultura e arte

Industrialização.

Agrotóxicos

Poluição do ar e dos rios.

Desmatamento.

Mudanças climáticas.

Desequilíbrio ecológico.

Alimentos transgênicos.

Poluição dos rios. Crise hídrica. Violência no campo.

Crimes contra ambientalistas.

Sociedade capitalista

Destruição ambiental.

Perda da diversidade.

Fonte: Anotações das Rodas de Conversa, (2018).

Para digitalização dos dados da pesquisa utilizou-se o software Microsoft Excel, onde foi realizada a tabulação dos dados. Em seguida, os dados obtidos foram analisados por intermédio de procedimentos de estatística descritiva, através 
do cálculo de frequências relativas, com resultados expressando o perfil de respostas fornecidas. Sendo a análise dos dados qualitativos realizada por meio de análise de Discurso do Sujeito Coletivo - DSC conforme descrito por Lefèvre e Lefèvre (2000).

\title{
RESULTADOS E DISCUSSÃO
}

Notou-se que $100 \%$ dos alunos que se manifestaram, destacaram no decorrer das discussões, variadas temáticas de forma interdisciplinar, abrangendo conteúdo das disciplinas de Biologia, Geografia, Filosofia, Sociologia, além de temas que também abrangiam a História e Artes. Percebeu-se que esta experiência de aprendizagem, ao colocar o aluno como protagonista do processo pedagógico, criou caminhos interessantes e instigadores, propiciando também interconexões entre os conteúdos e conhecimentos das disciplinas que compõem o currículo escolar, mas que, muitas vezes, encontram-se estanques e fragmentados.

Os dados apresentados expressam o perfil de resposta fornecido com maior frequência pelos alunos durante as rodas de conversa. Salienta-se que, devido ao compromisso ético na pesquisa, a identidade dos alunos foi preservada. Assim, as narrativas foram referenciadas com codinomes (nomes de árvores) e a série/turma:

\begin{abstract}
[...] A primeira estrofe da música que fala da variedade de biomas e logo em seguida já destaca o estrago em que se encontram em vários lugares do planeta. Não precisamos nem ir longe, basta olhar da área da escola a Serra da Jiboia e ver o estrago que já causamos ao meio ambiente. Só devastação, só destruição! Que tipo de progresso é esse? [...] (IPÊ - 3aㅡ B Mat., 2018).

[...] Vanessa da Mata ao destacar que a destruição é reflexo do humano e que a ambição desumana o ser, é um tapa na nossa cara, pois não adianta a agente querer pôr a culpa em ninguém. Somos nós os culpados, direta ou indiretamente pela situação do planeta, e acabou! Diretamente se não agimos corretamente pela preservação e indiretamente se nos acomodamos e deixamos para que os outros façam a nossa parte [...] (JATOBÁ - 3 ${ }^{a}$ A Mat., 2018).
\end{abstract}

Ipê narrou a diversidade de biomas existentes no mundo, ressaltando a destruição da diversidade ambiental (fauna e flora) para a realidade local, ou seja, o meio ambiente do município de Castro Alves/BA, especificamente da região de Mata Atlântica do município, na Serra da Jiboia, local de nascentes. Além disso, Ipê não se eximiu da culpa sobre os problemas ambientais. O mesmo fez Jatobá, ao destacar de forma pertinente e desconfortável a contribuição direta e indireta de todos para a situação ambiental e civilizatória atual.

[...] Desmatamos tudo e reclamamos que não está chovendo como antes. Muita hipocrisia, pois sabemos que isso é culpa de quem? A destruição da natureza é causada pelas nossas ações e ainda temos a cara de pau de reclamar do tempo. Jogamos lixo em tudo que é canto, mas quando chove e inunda a rua e a nossa casa a gente prefere culpar a prefeitura ou o vizinho [...] (JACARANDÁ - 3ª D Mat., 2018).

[...] Chamou minha atenção essa parte que fala do desequilibro ambiental e da alteração genética. Já discutimos isso em Geografia e Biologia. Quando uma espécie é extinta, desequilibra tudo, pois cada coisa tá ligada, não é? E aí tem o uso de agrotóxicos que matam as pragas da plantação, mas também envenenam os animais e a gente, também. Agora tem a questão dos alimentos transgênicos. Não se sabe se faz bem ou mal à nossa saúde, mas a gente já come. O que interessa no capitalismo é o lucro e só! [...] (CEDRO - 3 ${ }^{\mathrm{a}} \mathrm{A}$ Mat., 2018). 
Jacarandá enfatizou em sua narrativa a hipocrisia em relação às consequências da irresponsabilidade ambiental, desde as ações pessoais do cotidiano quanto aos problemas causados por terceiros. Já Cedro destacou o desequilibro ambiental, dos agrotóxicos e dos transgênicos, enfatizando que tais conteúdos já haviam sido trabalhados anteriormente, salientando a interligação dos fatores que compõem o ecossistema, pois quando há uma quebra na cadeia, o ecossistema pode se colapsar. Estas conclusões dos alunos são corroboradas por Miranda et al. (2016), ao ressaltarem as drásticas modificações físicas e biológicas nos ecossistemas, em função da exploração excessiva dos recursos naturais. Além disso, Cedro também salientou como os interesses capitalistas se sobrepõem sobre a saúde da população.

[...] Sujamos os rios, dependemos das águas. Só vou dar alguns exemplos para a gente discutir: O Rio Jaguaripe nasce aqui na cidade, está todo poluído pelo esgoto da cidade. Já nasce morto. O Rio Paraguaçu que abastece o município também está morrendo porque desmatam e jogam esgoto. O Rio São Francisco sempre é notícia na televisão falando para salvar o rio. Lembram que São Paulo teve problema com água há um tempo atrás. E lá tem rio na cidade...o Tietê, mas tá morto também. E aí, vão fazer o que quando estes rios morrerem de vez? [...] (AROEIRA, 3를 A Mat., 2018) [...] Muitos nem sabem que aqui, em Castro Alves, nasce um rio, pois ele tá todo canalizado e também virou um esgoto. Além de a gente poluir os rios, jogando esgoto de tudo que é tipo, ainda tem a questão do desmatamento que acaba com as nascentes. A gente sempre ouve que tá faltando água em algum lugar, mas acha que não vai acontecer com a gente. É como também diz na música: 'Essa imagem infértil do deserto. Nunca pensei que chegasse aqui'. Mas se a gente não cuidar direito do meio ambiente, um dia chega sim [...] (JUREMA, 3를 C Mat., 2018).

As narrativas de Aroeira e Jurema salientaram a poluição dos rios, inclusive destacando rios locais, regionais e nacionais. Enfatizaram a crise hídrica que já acomete inúmeras cidades, na Bahia ou noutras regiões do Brasil, seja devido à diminuição das chuvas ou pelo desmatamento das áreas de florestas e nascentes, o que para Miranda et al. (2016) representa o predomínio do antropocentrismo. Além disso, Aroeira e Jurema discutiram também a poluição dos rios brasileiros pelo esgoto, seja doméstico ou industrial, o que causa a morte dos rios tanto nas cidades pequenas, como Castro Alves, quanto nas grandes metrópoles, como Salvador, São Paulo e outras.

[...] Essa parte que fala dos meios violentos. Morto por dinheiro. A gente sempre vê na televisão alguma notícia sobre crimes contra pessoas que lutam pelo meio ambiente. $E$ fica por isso mesmo, ninguém é punido. É complicada a situação, pois a ganância do homem não respeita nada [...] (JEQUITIBÁ, 3ª A Mat., 2018).

A narrativa de Jequitibá trouxe à discussão os crimes cometidos contra ambientalistas no Brasil: como os casos de: Chico Mendes, em 1988, no Acre; da missionária Dorothy Stang, em 2005, no Pará e muitos outros que morreram defendendo os camponeses, índios e os demais povos da floresta ou dos sertões contra os interesses dos grandes fazendeiros. Como salientou Jequitibá, muitos dos crimes não são esclarecidos e/ou os culpados são punidos. 
[...] A última estrofe me chamou a atenção também, pois que desenvolvimento é esse que a gente vai destruindo tudo? Além disso, é muita ingratidão com o planeta. Como diz a música, somos a raposa vigiando o galinheiro, ou seja, tomando conta da natureza. Somos os cupins do planeta e estamos acabando com tudo [...] (SUCUPIRA, 3 ${ }^{\text {a }}$ B Mat., 2018).

[...] O último trecho da música traz uma metáfora bem legal e definiu muito bem a situação do mundo. Somos a raposa que toma conta do galinheiro. Estamos destruindo a natureza sem pensar em nós mesmos e nos nossos filhos. Progresso? Tá mais para regresso! [...] (PAU BRASIL, 3aㅡ A Mat., 2018)

Os alunos Sucupira e Pau Brasil evidenciaram as discussões ocasionadas pela última estrofe da música, demonstrando os problemas gerados pelo sistema capitalista na apropriação e extração dos recursos naturais do planeta. Nisso, os alunos discutiram o modelo de desenvolvimento atual e como isso compromete o futuro da humanidade. Assim, há uma necessidade de repensar os valores que norteiam a sociedade em relação à produção e ao consumo dos bens e alimentos, bem como as inter-relações que são mantidas com a natureza. Estas descrições estão de acordo com a narrativa de Loureiro (2005) ao afirmar que o futuro da humanidade depende da relação estabelecida com os recursos naturais disponíveis, por isso, a educação ambiental vem sendo considerada cada vez mais urgente na sociedade.

$\mathrm{Na}$ avaliação da atividade, os alunos enfatizaram a importância da música para a apreensão dos conteúdos disciplinares e para tornar as aulas mais lúdicas:

[...] A música torna a aula mais interessante e divertida, sem a mesmice de sempre. As músicas tratam de vários assuntos e assim podemos entender e discutir melhor os assuntos através das letras dessas músicas. Infelizmente, nem todos os professores trabalham músicas [...] (JATOBÁ, $3^{\underline{a}}$ A Mat., 2018).

[...] A música nos faz refletir sobre determinados assuntos. E algumas músicas não saem da nossa cabeça, o que faz que, no momento certo, a gente se lembre do assunto e consiga responder à avaliação. Eu gosto quando trabalhamos com música [...] (CEDRO, 3를 A Mat., 2018).

As narrativas mostraram que, apesar da música ser uma estratégia de aprendizagem interessante para estimular a criticidade e a reflexividade dos alunos, muitos professores ainda resistem em utilizá-las nas suas aulas ou quando utilizam, não as exploram como deveriam, ou seja, não tornam a música fomentadora de questionamentos e discussões sobre os conteúdos trabalhados, retirando assim as possibilidades de um ensino e aprendizagem mais autônomo e reflexivo (BRASIL, 2018). Neste contexto, Bernades e Nehme (2017) e Souza e Conceição (2018) destacam o uso da música como estratégia de aprendizagem, tendo em vista o caráter dialógico desta atividade, despertando no aluno maior interesse pelos conhecimentos trabalhados em sala de aula.

As discussões sobre os problemas e as responsabilidades ambientais contemporâneos, encaminhadas e aprofundadas nas rodas de conversa, a partir da música Absurdo (Vanessa da Mata), revelaram percepções e questionamentos pertinentes por parte dos alunos, inclusive aliando os conhecimentos discutidos com a realidade vivida. Muitas vezes os alunos, nas argumentações e reflexões, ultrapassaram, mesmo sem sentir ou se importar, as barreiras curriculares impostas por uma estruturação cartesiana das disciplinas escolares, articulando conceitos e conhecimentos para explicar ou questionar os problemas civilizatórios/ambientais 
vivenciados na atualidade, inclusive na escala local. Notou-se também a concordância dos demais alunos em relação aos estudantes que primeiramente se manifestavam, à medida que esses reafirmam o que acabara de ser relatado por seu colega.

O ser humano vive em um mundo dinâmico, complexo e contraditório. São presenciados, na contemporaneidade, o agravamento dos problemas ambientais, consequência da crise civilizatória que atinge os diversos setores da sociedade. Nesse sentido, a escola deve propiciar os instrumentos necessários para que os alunos possam compreender os processos, interconexões, tensões e conflitos que fundamentam a realidade, a fim de que se sensibilizem, questionem e modifiquem valores, relações e práticas para a construção de um outro olhar e postura perante o meio ambiente. Neste sentido de acordo com Vieira et al. (2020) a educação ambiental surge como importante ferramenta na resolução de problemas socioambientais atuais, ao passo que possibilita resgatar valores essenciais para a cidadania.

\section{CONCLUSÕES}

Evidenciou-se que a música se constitui em uma estratégia pedagógica que propicia a reflexão para a produção do conhecimento, contribuindo para se trabalhar a Educação Ambiental de maneira efetiva, pois estimulou e agregou importantes contribuições no âmbito da conservação ambiental e sustentabilidade. Deste modo, espera-se, que este trabalho possa colaborar para a efetivação de outras práticas e experiências de ensino e aprendizagem que ensejem mudanças nas práticas ambientais dos educandos, à medida que a Educação Ambiental, além de pertinente é também urgente e necessária.

\section{REFERÊNCIAS}

ABREU, C. R. O campo de pesquisa da Educação Ambiental e suas relações com o tema mudanças climáticas. Dissertação de Mestrado em Ensino de Ciências, Universidade Estadual de Goiás, Anápolis, Goiás. 71p. 2017.

AMARAL, I. A. Programa e ações de formação docente em educação ambiental. In: TAGLIEBER, José Erno; Guerra, Antônio Fernando Silveira (Orgs.). Pesquisa em educação ambiental: pensamentos e reflexões de pesquisadores em educação ambiental. Pelotas: Ed. E Gráf. Universitária, p. 145-167, 2005.

ASSMANN, H. Reencantar a educação: rumo à sociedade aprendente. Petrópolis, RJ: Vozes, 2003.

BERNADES, M.B.J; NEHME, V.G.F. A PESQUISA-AÇÃO: mediadora de ações em educação ambiental. Espaço em Revista, v. 19, n. 2, p. 56-67, 2017. Disponível em: $<$ https://www.revistas.ufg.br/espaco/article/view/51870>.

BERTONCELLO, L.; SANTOS, M. R. Música aplicada ao ensino da informática em ensino profissionalizante. Iniciação Científica CESUMAR, v. 4, n. 2, p. 131-142, 2002.

<https://periodicos.unicesumar.edu.br/index.php/iccesumar/article/view/62/38>. 
BRASIL. Secretaria de Educação Fundamental. Parâmetros curriculares nacionais: introdução aos parâmetros nacionais. Brasília: MEC, 1997. 126p, 2018. Disponível em: <http://portal.mec.gov.br/seb/arquivos/pdf/livro01.pdf>.

BURSZTYN, M.; EIRO, F. Mudanças climáticas e distribuição social da percepção de risco no Brasil. Mudanças climáticas e distribuição social da percepção de risco no Brasil. Revista Sociedade e Estado, v. 30, n. 2, 2015. Disponível em: <https://www.scielo.br/pdf/se/v30n2/0102-6992-se-30-02-00471.pdf>. DOI: 10.1590/S0102-699220150002000010.

CANTARELI, C. V.; MARTINS, R.; ARANTES, V.; RAMIRES, M.; BARRELLA, W. Levantamento preliminar de aves na foz do rio Una, Mosaico da Juréia-Itatins, São Paulo, Brasil. Unisanta Bioscience, v. 4, n. 1, p. 120-128, 2016. Disponível em: <http://ojs.unisanta.br/index.php/bio/article/view/632>.

LEFÈVRE, F.; LEFÈVRE, A. M. C; TEIXEIRA, J. J. V. O discurso do sujeito coletivo: uma nova abordagem metodológica em pesquisa qualitativa. Caxias do Sul: EDUCS, 2000.

LOUREIRO, C. F. B. Teoria Crítica. In: FERRARO-JUNIOR, L. A. Encontros e Caminhos: formação de educadores ambientais e coletivos educadores. $p$. 323-332; Brasília: Ministério do Meio Ambiente, Diretoria de Educação Ambiental, 2005.

<http://www.mma.gov.br/estruturas/educamb/_arquivos/encontros.pdf>.

Disponível:

MATA, V. Absurdo. Álbum Sim. Faixa 08, 2007. Disponível em: <http://www.vanessadamata.com.br/musicas-faixas.aspx?ID=3>.

MIRANDA, S.C.; ABREU, C.R.; DE-CARVALH, P.S. As mudanças climáticas no contexto da Educação Ambiental. In: PORTO, M.D.; SANTOS, M.L.; FERREIRA, J.R. Os desafios do Ensino de Ciências no século XXI e a formação de professores para a Educação Básica. Curitiba-PR: CRV, 2016.

SOUZA, H. R.; CONCEIÇÃO, E. G. Melodias urbanas: cantando e decifrando a cidade nas aulas de Geografia. In: PORTUGAL, Jussara Fraga (Org.). Educação Geográfica - diversas linguagens. Salvador: EDUFBA, p. 119-140, 2018.

WELLER, W. Grupos de discussão: aportes teóricos e metodológicos. In: WELLER, Wivian. PFAFF, Nicolle (Orgs.). Metodologias da pesquisa qualitativa em educação. - 3ª ed. - Petrópolis/RJ: Editora Vozes, p. 54-66, 2013.

VIEIRA, R. L. A.; BENTO, H. J.; SOUZA, H. R.; COSTA, C. M.; ANDREA, M. V. Avifauna do Campus da Universidade Federal do Recôncavo da Bahia, Cruz Das Almas - BA. Enciclopédia Biosfera, v. 16 n.29; p. 1901-1910, 2019. Disponível em:< http://www.conhecer.org.br/enciclop/2019a/bio/avifauna.pdf>. DOI: 10.18677/EnciBio_2019A147.

VIEIRA, R. L. A.; SOUZA, H. R.; COSTA, T. S. O.; COSTA, C. M.; ANDREA, M. V. Um diálogo entre ciência e cultura: concepções prévias dos alunos de ensino fundamental acerca das serpentes - um estudo de caso. Enciclopédia Biosfera, v. 17 n. 31, p. 240-249 2020. Disponível em:< 
http://www.conhecer.org.br/enciclop/2020A/um\%20dialogo.pdf>.

DOI:

10.18677/EnciBio_2020A23. 